\title{
Study of incidence and different aspects of cervical malignancy in tertiary centre of Jharkhand, India
}

\author{
Bijeta*, Neelam Nalini
}

Department of Obstetrics and Gynecology, Rajendra Institute of Medical Sciences, Ranchi, Jharkhand, India

Received: 15 May 2017

Accepted: 10 June 2017

\section{*Correspondence:}

Dr. Bijeta,

E-mail: bijeta.2106@gmail.com

Copyright: ( $)$ the author(s), publisher and licensee Medip Academy. This is an open-access article distributed under the terms of the Creative Commons Attribution Non-Commercial License, which permits unrestricted non-commercial use, distribution, and reproduction in any medium, provided the original work is properly cited.

\begin{abstract}
Background: Among the various killers of women of developing world, cervical cancer remains high in the list. Cervical cancer is the second most common cancer in women worldwide and the most common cancer in developing nations. The aim of the study was to determine the incidence of cervical cancer in post-menopausal women in Jharkhand and to determine various risk factors.

Methods: The study was conducted on post-menopausal females presenting in outpatient department, emergency and indoor patients admitted in the department of Gynecology and Obstetrics at Rajendra Institute of Medical Sciences, Ranchi from March 2015 to September 2016. All post-menopausal women patients with suspected or proved cervical malignancy were included in the study.

Results: The incidence of cervical cancer in this study was $16 \%$. Maximum number of cases with cervical malignancy was in the age of 51-60 (45.83\%). 45.83\% of cases belonged to Hindu community. Maximum number of cases belonged to low socio-economic group (66.66\%). $45.83 \%$ of cases were para 5 or more Most of the patient had more than one complains. Post-menopausal bleeding was commonest complain present in $66.66 \%, 77.08 \%$ came in advance stage (stage IIb+ III+ IV).

Conclusions: This study showed UA-S/D ratio and UA-RI $>2$ SD are significant predictors of perinatal deaths and immediate neonatal resuscitation in preeclampsia. Acute fetal distress in labour or neonatal nursery admission could not be predicted.
\end{abstract}

Keywords: Biopsy, Histopathology, Parity

\section{INTRODUCTION}

Among the various killers of women of developing world cervical cancer remains high in the list. Cervical cancer is the second most common cancer in women worldwide and the most common cancer in developing nations. It targets women between the ages of 15 and 45 and ends 288,000 lives per year. According to WHO, there are 510,000 new cases every year, with $80 \%$ occurring in developing nations half of these cases end in death. ${ }^{1}$

Cervical cancer is considered a preventable disease by WHO because it can be diagnosed in its precancerous phase. Therefore, it is a disease which can be controlled. This has been achieved in most parts of the developed countries by screening. Data showed that in areas where screening has been carried out for a sufficient period of time which means 10-15 years, both the incidence and mortality of invasive cancer have been reduced. ${ }^{2}$ Although all etiological factors are not known, it is a disease related to sexual activity.

The contributory risk factors are (a) Sexual behaviourage at commencement of sexual activity, number of sexual partners (b) Multiparity (c) Sexually transmitted 
diseases especially HPV (d) Low socio-economic status (e) Smoking etc.

The natural history of cervical cancer is favorable for effective screening. In India, on one side there is early marriage, early age of pregnancy, multiparity, poor genital hygiene, illiteracy and poor socio-economic condition which increases the risk of cervical cancer and on the other side lack of funds, trained personnel and laboratory facilities prevents a mass screening program for detection of preclinical conditions of cervical cancer. The same is true of our state, Jharkhand, where no effective mass screening has been undertaken as yet because of illiteracy.

Mass screening is expensive. In our country where population is increasing day by day and resources are limited, screening may be conducted on a segment of a population at relatively high risk.

High risk groups can be identified by previous epidemiological studies. Women who attend the hospital for any complaint can be screened for cervical cancer. Women can be screened for several conditions at same sitting like breast and genital tract cancer. It has been found to be very useful and will reduce the cost.

Very few studies have been done in postmenopausal group of females regarding cervical carcinoma. Though they are highly vulnerable and prone to develop these cancers at the climax of their lives but they remain neglected both by the society and researchers.

The objectives of the study were to determine the incidence and prevalence of cervical cancer in postmenopausal women in Jharkhand and to determine the various risk factors of cervical cancer among the postmenopausal women in Jharkhand.

\section{METHODS}

The study was conducted on post-menopausal females presenting in outpatient department, Gynecology emergency and indoor patients admitted in the Department of Gynecology and Obstetrics at Rajendra Institute of Medical Sciences, Ranchi from March 2015 to September 2016.

\section{Inclusion criteria}

All post-menopausal women patients with suspected or proved cervical malignancy.

\section{Exclusion criteria}

- Symptoms proved to be due obvious nongynecological cause

- Women not attained menopause.

\section{Methods}

Detail history of the patients were taken. Thorough general and pelvic examination was done.

\section{Pelvic examination}

- Inspection of the vulva and introitus for any obvious lesion or discharge.

- Inspection per speculum: vagina, cervix and fornices were inspected for

- gross appearance of cervix

- Any growth, erosion, ulcer.

- Nature of discharge

- Any contact bleeding during examination

\section{Per rectal examination}

- To know the condition of rectal mucosa

- To know the infilteration of parametrium and uterosacral ligaments.

- Proper assessment of size, shape and mobility of uterus

\section{Examination under anaesthesia}

To confirm pelvic examination findings and also for better assessment. Biopsy was taken in same sitting.

\section{Investigations}

\section{Laboratory}

- Complete Haemogram

- Blood sugar fasting and pp

- ESR

- Bleeding and clotting time

- Liver function test- liver metastasis

- Renal function test- renal impairment or obstruction

- Urine analysis- Routine examination, $\mathrm{C} / \mathrm{S}$

\section{Radiological}

- Ultrasonography-whole abdomen \& pelvis

- Chest radiograph- lung metastasis

- Intravenous pyelogram- hydronephrosis

- CT Scan (abdomen and pelvis): lymph node metastasis, metastasis to other organs and hydronephrosis.

- MRI Scan- local extra cervical invasion, lymph node metastasis.

\section{Procedural}

- PAP smear

- Cervical biopsy and EUA

- Colposcopy

- Dilatation of cervix and endometrial curettage. (for HPE) 
Cystoscopy and proctoscopy

tumor invasion to bladder and rectum (if required). Pap smear results were analysed on the basis of Bethesda system.

\section{RESULTS}

The study was conducted from March 2015 to September 2016 in Department of Obstetrics and Gynecology, Rajendra Institute of Medical Science. During this period, all the postmenopausal patients who attended Gynecology OPD, Gynecology emergency or admitted in indoor of Rajendra Institute of Medical Science (Gynecology and Oncology) were included in the study except those having some obvious non-gynaecological cause. Total number of patient who fulfilled the inclusion criteria were 368 , but only 300 patients had given consent. Postmenopausal patients considered were those with amenorrhea for at least 1 year.

All patients in the study were more than forty years of age. Maximum numbers of patients were observed in the age range 41-50 years and minimum number in the age range 71-80 years. The population under study was divided into two major sections, the tribals and nontribals. $75.33 \%$ patients belonged to non-tribal group. $42.60 \%$ patients belonged to tribal group.

Patients belonging to the four main religions were found to be reporting at study hospitals- Hindus, Muslims, Christians and Sarnas. Post-menopausal women of other religions did not report to the hospital in the study period. Maximum patients (49.33\%) patients belonged to Hindu community. On the basis of their income patients were classified into three major socioeconomic groups. Maximum patients $(53.33 \%)$ belonged to low socioeconomic status. In the present study group mean age at marriage was 16.5 years. Parity was divided into two groups, $\mathrm{P}<5$ and $\mathrm{P}>5$. In the present study $60 \%$ patients were para 5 or more. Out of 300 patients there was a history of use of some form of contraceptive measures in 184 patients which constituted $61 \%$ of the study group. Majority of the cases who had used contraceptive measures belonged to middle socio-economic status. Permanent method i.e. female sterilization was the preferred method in the present study. During the study period, out of 300 enrolled patients 48 (16\%) were diagnosed to have carcinoma cervix (Table 1).
Table 1: Incidence of cervical cancer.

\begin{tabular}{|ll|}
\hline Total no. of patients & 300 \\
\hline Patients with cervical cancer & $48(16 \%)$ \\
\hline
\end{tabular}

Patients were suspected either on basis of pap smear or clinically. But ultimately all the cases were confirmed by cervical biopsy.

One case presented after hysterectomy with histopathological report suggestive of cervical carcinoma (squamous cell carcinoma). Maximum no of cases with cervical malignancy were in the age of 51-60 (45.83\%). 3 patients were presented at the age of $>70$ years (Table 2 ).

Table 2: Case according to age group.

\begin{tabular}{|lll|}
\hline Age (years) & No. of patients & $\%$ \\
\hline $41-50$ & 16 & 33.33 \\
\hline $51-60$ & 22 & 45.83 \\
\hline $61-70$ & 7 & 14.58 \\
\hline$>70$ & 3 & 06.25 \\
\hline$(n=48)$ & & \\
\hline
\end{tabular}

$45.83 \%$ of cases belonged to Hindu community. $16.66 \%$ of cases belonged equally from Muslim and Christian community (Table 3).

Table 3: Cases of cancer cervix according to religion.

\begin{tabular}{|lll|}
\hline Religious & No. of patients & $\%$ \\
\hline Hindu & 22 & 45.83 \\
\hline Muslim & 8 & 16.66 \\
\hline Christian & 8 & 16.66 \\
\hline Sarnas & 10 & 20.83 \\
\hline$(n=48)$ & & \\
\hline
\end{tabular}

Maximum no. of cases belonged to low socio-economic group (66.66\%) (Table 4). $45.83 \%$ of cases were para 5 or more (Table 5$)$.

Table 4: Case according to socio-economic status.

\begin{tabular}{|c|c|c|}
\hline Socio-economic status & No. of patients & $\%$ \\
\hline Low & 32 & 66.66 \\
\hline Medium & 15 & 31.25 \\
\hline High & 1 & 02.08 \\
\hline
\end{tabular}

Table 5: Case according to parity.

\begin{tabular}{|llllllll|}
\hline parity & Nullipara & Para 1 & Para 2 & Para 3 & Para 4 & Para 5 & $>$ para 5 \\
\hline No. of patients & Null & 1 & 4 & 5 & 6 & 10 & 22 \\
\hline percentage & & 02.08 & 8.3 & 10.4 & 12.5 & 20.83 & 45.83 \\
\hline
\end{tabular}


More than $65 \%$ of cases conceived before the age of 20 years. In the study group $1 / 4$ th of cases (29.16\%) were addicted to tobacco for more than 5 years. Most of the patient had more than one complains.

Post-menopausal bleeding was commonest complain present in $66.66 \%$. Second most common complaint was pain lower abdomen present in $58.33 \%$ of cases. Watery and blood mixed discharge per vagina was present in $41.66 \%$ of cases (Table 6).

\section{Table 6: Distribution of cases according} to chief complaint.

\begin{tabular}{|llc|}
\hline Presenting complaint & No. of patients & $\%$ \\
\hline Postmenopausal bleeding & 32 & 66.66 \\
\hline $\begin{array}{l}\text { Watery discharge per } \\
\text { vaginum }\end{array}$ & 20 & 41.66 \\
\hline Blood stained discharge & 20 & 41.66 \\
\hline Contact bleeding & 06 & 08.33 \\
\hline $\begin{array}{l}\text { Something coming out } \\
\text { per vaginum }\end{array}$ & 07 & 04.16 \\
\hline Foul smelling discharge & 15 & 31.25 \\
\hline $\begin{array}{l}\text { Pain in lower abdomen, } \\
\text { backache }\end{array}$ & 28 & 58.33 \\
\hline
\end{tabular}

It was observed that only 11 patients $(20.91 \%)$ out of 48 presented as stage IB or IIA cancer cervix while 37 patients $(77.08 \%)$ came in advance stage (stage IIb + III + IV) (Table 7).

Table 7: Cases according to clinical staging.

\begin{tabular}{|llll|}
\hline \multicolumn{2}{|c|}{ Clinical stages } & No. of cases & $\%$ \\
\hline \multirow{2}{*}{ I } & $\mathrm{A}$ & 0 & 00.00 \\
\cline { 2 - 4 } & $\mathrm{B}$ & 7 & 14.58 \\
\hline \multirow{2}{*}{ II } & $\mathrm{A}$ & 4 & 08.33 \\
\cline { 2 - 4 } & $\mathrm{B}$ & 13 & 27.08 \\
\hline \multirow{2}{*}{ III } & $\mathrm{A}$ & 4 & 08.33 \\
\hline \multirow{2}{*}{ IV } & $\mathrm{B}$ & 18 & 37.50 \\
\hline
\end{tabular}

The most common histological type of cervical cancer was squamous cell carcinoma present in $43(89.58 \%)$ cases. In maximum $(81.39 \%)$ the histology showed grade II differentiation according to broder's classification.

Out of 11 cases (IB + IIA) 3 patients had radical hysterectomy and 6 patients had radical hysterectomy followed by radio therapy.

One patient was diagnosed as stage IB but when abdomen was opened the uterus was found to be fixed posterior abdomen closed and later on patient was referred for radio therapy. Pelvic lymph node removed in all cases sent for histo-pathological examination.

\section{DISCUSSION}

The incidence of cervical carcinoma in our study was $16 \%$. A similar study was conducted in Delhi by Jitendra Nigam $\mathrm{S}$, et al. ${ }^{3}$ The study population included women with poor socioeconomic class and included both pre-and postmenopausal subjects. The overall incidence of carcinoma cervix in the study was $12.5 \%$. Demographic profile and data were collected retrospectively from tertiary care centers of west Delhi from 2004 to 2011. Thus, the present study shows the incidence of cervical malignancy near to this study. But the small difference in both the studies may be due to inclusion of premenopausal women in other study and difference in geographical, racial and genetic profile. Also, the later study was retrospective.

Among 48 positive cases commonest method was clinical examination. $56.25 \%$ cases were diagnosed to have cervical malignancy in OPD or indoor by just proper clinical examination. But directly or indirectly all of them were subjected to tissue diagnosis. PAP smear and cervical biopsies played important role and 10 cases were diagnosed by each of them. Only one patient presented to us with a positive histopathological for cervical carcinoma following hysterectomy. As per cancer survivor reports, only a good history with meticulous clinical examination is enough for diagnosis of carcinoma cervix in most of the cases. This supports our study.

The maximum positive cases were in age group 51-60 years $(22 / 48$ i.e. $45.83 \%)$ followed by $41-50$ years $(16 / 48$ i.e. $33.33 \%)$. The incidence was lesser in higher age group which may be related to lesser number of participants in those groups due to mortality and dependence.

The incidence of carcinoma cervix was highest in Hindu patients followed by Sarnas, but Christian and Muslims had the least number of cases. But going into details the incidence within each religious group (Table 3) the incidence is highest within the Muslim females $(21.05 \%)$ compare to average $(16 \%)$. The high incidence within the group may be related to higher parity, poor hygiene other socioeconomic factors. In their study Matin et al, found that the Muslim women resist screening practices that are the standard in the US, which threaten their cultural and religious values. The women were less enthusiastic and candid in discussing highly sensitive and taboo topics. ${ }^{4}$ Thus social behavior based on religion in these females may be responsible for inaccurate picture of carcinoma cervix in them.

As per our study cervical cancer is more common in low socioeconomic class. In the study epidemiology of cancer of the cervix: global and national perspective, Shanta V et al, suggested socioeconomic factors (education and income) one of the important determinant of cancer cervix. $^{5}$ 
Majority of our patients (30/48 i.e. $62.5 \%)$ were married between the age of 15-21 years while 14 (14/48 i.e. $29.1 \%$ ) patients were married after the age of 21 years. Thus, early marriage indicates the earlier onset of sexual activity and prolonged sexual life. Thus, more chances of HPV infection and higher incidence of cervical carcinoma. In their study related to age at marriage and cervical cancer incidence, Prabhakar AK et al, concluded younger age of marriage is clearly a risk factor for carcinoma cervix. $^{6}$

They said that age at marriage has been recognised as a major risk factor associated with cervical cancer. Over the past 8 decades there has been a rise in age at marriage varying from 14 years to 18 years. Consequently, a significant reduction of cervical cancer cases and 6.3 percent reduction in the incidence of invasive cervical cancer is observed. Similarly, early age at marriage and increasing parity are related to increased incidence of cervical malignancy.

As stated earlier longer the duration of sexual activity and more child bearing definitely associate with HPV infection and ultimately leading to carcinoma of cervix. Similar facts were found in study by Muñoz N et al, they conducted a multicentre case control study under International Agency for Research on Cancer (IARC) and published their results in the year 2002. ${ }^{7}$ They concluded high parity increases the risk of squamous-cell carcinoma of the cervix among HPV-positive women. A general decline in parity might therefore partly explain the reduction in cervical cancer recently seen in most countries.

Tobacco as a risk factor for cervical carcinoma which shows that 14 among 48 cases $(29.16 \%)$ had tobacco addiction (chewing or smoking). Studies clearly show role of tobacco in cervical and other carcinomas. As per American Cancer Society women those who smoke are having chances of cervical carcinoma twice than nonsmokers. In journal of virology of American Society for Microbiology Castle PE described that tobacco smoke is a well-established human papillomavirus (HPV) cofactor for the development of cervical precancer and cancer but the molecular mechanisms by which smoking increases the risk of cervical precancer and cancer remain unknown. ${ }^{8}$ There are several plausible explanations. One is that smoking inhibits the immune response to HPV. A second is that carcinogenic HPV-infected cells are exposed to smoking carcinogens that cause DNA damage while HPV oncoproteins block apoptosis and cell cycle arrest.

In present study, maximum cases presented in advanced stages either IIB $(27.08 \%)$ or IIIB $(37.50 \%)$. Anorlu RI et al, presented the result of their study- late presentation of patients with cervical cancer to a tertiary hospital in Lagos: what is responsible?. ${ }^{9}$ In their study concluded that patients' delay in seeking healthcare and care providers' delay in referring patients to a tertiary hospital contributed to the late presentation.

Among the study cohort maximum number of patient had squamous cell carcinoma. Worldwide incidence of squamous cell carcinoma has ranked one among the various types of cervical carcinoma with its obvious association with HPV infections. Also, studies from India support the same results. In a study by Kulkarni reveals that multiple infection of HPV 16 and 18 is quite high in cervical cancer and specially in squamous cell carcinoma. $^{10}$ Hence, considering the possibility of promotion of vaccines for prevention of cervical cancer would be a wiser approach to decrease the incidence of cervical cancer.

\section{CONCLUSION}

Cancer of the uterine cervix is the commonest cancer among Indian women accounting for $20 \%$ of the total cancer incidence in Indian population. The incidence of cervical carcinoma was $16 \%$ among total postmenopausal women enrolled in the study during study period. In spite of being a preventable cancer with various screening modalities, the incidence of cervical cancer is very high in developing countries. Various health programs should be conducted to screen women for cervical cancer as well as to create awareness among general population. Also, vaccination against Human Papilloma Virus in all young girls should be considered in order to prevent this disease.

\section{ACKNOWLEDGMENTS}

Authors would like to thank all the faculty members and post-graduate students who helped in completion of this article.

\section{Funding: No funding sources Conflict of interest: None declared \\ Ethical approval: The study was approved by the Institutional Ethics Committee}

\section{REFERENCES}

1. United Nations, authors. UN Millennium Development Goals Available from; http://www.un.org/millenniumgoals/.

2. Bruce J, Clark S. Including Married Adolescents in Adolescent Reproductive Health and HIV/AIDS Policy. Geneva, Switzerland: World Health Organization; 2003.

3. Nigam JS, Yadav P, Sood N. A retrospective study of clinico-pathological spectrum of carcinoma breast in a West Delhi, India. South Asian J Cancer. 2014;3:179-81.

4. Matin M, LeBaron S. Attitudes toward cervical cancer screening among Muslim women: a pilot study. Women and health. 2004;39(3):63-77.

5. Shanta V, Krishnamurthi S, Gajalakshmi CK, Swaminathan R, Ravichandran K. Epidemiology of 
cancer of the cervix: global and national perspective. J Indian Medl Assoc. 2000;98:49-52.

6. Prabhakar AK, Menon GR. Age at marriage and cervical cancer incidence. Indian $\mathrm{J}$ Cancer. 1995;32:63-8.

7. Muñoz N, Bosch FX, de Sanjosé S, Herrero R, Castellsagué X, Shah KV, et al. Epidemiologic classification of human papillomavirus types associated with cervical cancer. New England J Med. 2003;348(6):518-27.

8. Castle PE. How Does Tobacco Smoke Contribute to Cervical Carcinogenesis? J Virol. 2008;82(12):60846.

9. Anorlu RI, Orakwue CO, Oyeneyin L, Abudu O. Late presentation of patients with cervical cancer to a tertiary hospital in Lagos: what is responsible? Eur $\mathbf{J}$ Gynaecol Oncol. 2004;25(6):729-32.

10. Kulkarni SS, Kulkarni SS, Vastrad PP, Kulkarni BB, Markande AR, Kadakol GS, et al. Prevalence and distribution of high risk human papillomavirus (HPV) types 16 and 18 in carcinoma of cervix, saliva of patients with oral squamous cell carcinoma and in the general population in Karnataka, India. Asian Pac J Cancer Prev. 2011;12(3):645-8.

Cite this article as: Bijeta, Nalini N. Study of incidence and different aspects of cervical malignancy in tertiary centre of Jharkhand, India. Int J Reprod Contracept Obstet Gynecol 2017;6:311823. 